\title{
Laparoscopic Crural Repair With Simultaneous Sleeve Gastrectomy: A Way in Gastroesophageal Reflux Disease Treatment Associated With Morbid Obesity
}

\author{
Ayman M. Soliman ${ }^{1,2,3^{*}}$, Hesham Maged ${ }^{1}$, Ahmed M. Awad ${ }^{1}$, Osama El-Shiekh ${ }^{1}$ \\ ${ }^{1}$ Department of General Surgery, Ain Shams University Hospital, Cairo, Egypt \\ ${ }^{2}$ Department of General Surgery, Dr. Suliman Fakeeh Hospital, Jeddah, Saudi Arabia \\ ${ }^{3}$ Department of General Surgery, Al Mouwasat Hospital, Dammam, Saudi Arabia
}

A R T I C L E I N F O

Article type:

Original Article

Article history:

Received: 11 Apr 2012

Revised:30 April 2012

Accepted: 07 May 2012

Keywords:

Laparoscopy

Hernia, Hiatal

Gastrectomy

\begin{abstract}
A B S T R A C T
Background: Laparoscopic sleeve gastrectomy (LSG) has become popular both as a definitive and a staged procedure for morbid obesity. Gastroesophageal reflux disease (GERD) is a common co-morbid disease in bariatric patients.

objectives: The aim of this study was to evaluate the efficacy of LSG and hiatal hernia repair (HHR) to treat obesity, complicated by hiatus hernia (HH).

Patients and Methods: The participants in the study were twenty patients, 14 women and 6 men, with a mean body mass index of $43.4 \pm 1.9 \mathrm{~kg} / \mathrm{m}^{2}$ and mean age of 47 years. All the subjects were eligible for LSG and eight were found to have esophagitis at preoperative endoscopy. Patients with Barrett's esophagus were excluded. GERD symptom questionnaire, 24-hour esophageal pH-metry, and manometry were employed as Preand post-procedure assessments. The mean follow-up period was eight months. Clinical outcomes were also evaluated in terms of GERD symptoms improvement or resolution, interruption of antireflux medication, and X-ray evidence of $\mathrm{HH}$ recurrence.

Results: Symptomatic HH was diagnosed preoperatively in 18 patients. In the other two patients, $\mathrm{HH}$ was asymptomatic and was diagnosed intra-operatively. Prosthetic reinforcement of crural closure was performed in two symptomatic cases with an $\mathrm{HH}>5$ $\mathrm{cm}$. Mortality was nil and no complications occurred. After a mean follow-up of seven months, GERD symptoms resolution occurred in nine patients, while the other patients reported an improvement of reflux. Body mass index had fallen from 43.4 to $36.2 \mathrm{~kg} / \mathrm{m}^{2}$. Conclusions: A laparoscopic hiatal repair with or without commercially available onlay reinforcement biologic mesh and a sleeve gastrectomy performed at the same time, was successful in controlling the reflux symptoms and reducing body weight.
\end{abstract}

Implication for health policy/practice/research/medical education:

The research aims to improve the outcome for obese patients after laparoscopic sleeve gastrectomy as most of them have symptoms of reflux.

Please cite this paper as:

Soliman AM, Maged H, Awad AM, El-Sheikh O. Laparoscopic Crural Repair With Simultaneous Sleeve Gastrectomy: A Way in Gastroesophageal Reflux Disease Treatment Associated With Morbid Obesity. J Minim Invasive Surg Sci. 2012; 1(2): 67-73. DOI: 10.5812/ jmiss.5171

* Corresponding author: Ayman Mohamad Shaker Soliman, Department of General Surgery, Ain Shams University Hospital, Cairo, Egypt. Tel: +966501140457, Fax:+96-638950767,_E-mail: shaker_ayman2004@hotmail.com DOI: $10.5812 / j$ miss.5171

Copyright (c) 2012, Minimally Invasive Surgery Research Center and Mediterranean \& Middle Eastern Endoscopic Surgery Association. This is an open-access article distributed under the terms of the Creative Commons Attribution License, which permits unrestricted use, distribution, and reproduction in any medium, provided the original work is properly cited.

\section{Background}

Obesity is associated with a significantly increased risk of gastroesophageal reflux disease and recurrence of reflux symptoms following surgical intervention in patients, compared to individuals with normal body-mass 
index (BMI) (1). In west the prevalence of GERD and obesity has increased significantly over the past 40 years, suggesting a link between these two disorders $(2,3)$. The severity of reflux symptoms and obesity is associated with a decreased quality of life (2). Changes in gastroesophageal anatomy and physiology caused by obesity may explain the association (4). They include an increased prevalence of esophageal motor disorders, diminished lower esophageal sphincter (LES) pressure, the development of a hiatal hernia $(\mathrm{HH})$, and increased intragastric pressure (5). Hiatal hernia is commonly associated with symptomatic GERD, and patients with abnormal esophageal acid exposure have a significantly higher prevalence of hiatal hernia (6). Obesity has proved to be a significant independent risk factor for the development of GERD and/or $\mathrm{HH}$; about $50-70 \%$ of patients undergoing bariatric surgery for morbid obesity have a symptomatic reflux, while symptomatic $\mathrm{HH}$ is present in $15 \%$ of patients with a body mass index $(\mathrm{BMI})>35 \mathrm{~kg} / \mathrm{m}^{2}$. GERD and $\mathrm{HH}$ are associated with increased BMI (7). The prevalence of GERD (defined as abnormal acid exposure and/or mucosal fissures) was $41 \%$ before laparoscopic sleeve gastrectomy (LSG) and rose significantly to $71 \%$ after $\operatorname{LSG}(8,9)$.

Bariatric surgery and its effects on a number of obesityrelated disorders have been studied more extensively, Roux-en-Y gastric bypass (RYGB) has been consistently associated with improvement in the symptoms and findings of GERD (10). The mechanism of action through which this surgery is successful at improving GERD may be independent of weight loss and needs further researches. Current evidence suggests that laparoscopic adjusted gastric banding should be avoided in these patients as the impact on gastroesophageal reflux disease appears unfavorable (11). Laparoscopic antireflux surgery (LARS) is considered as the gold standard for the treatment of GERD and/or HH (11). A prosthetic-reinforced hiatoplasty seems to reduce the risk for postoperative disruption of hiatal repair significantly (12). Nevertheless recent studies have demonstrated that obesity plays an adverse role on long-term clinical outcomes of Laparoscopic antireflux surgery (LARS) (13). As a result, bariatric procedures such as laparoscopic gastric banding (LGB) with hiatal hernia repair (HHR) and laparoscopic Roux-en-Y gastric bypass (LRYGBP) have been proposed, by several authors, for the synchronous treatment of morbid obesity and GERD with or without $\mathrm{HH}$, as treatments which are providing good results in terms of excess weight loss and reflux symptoms improvement $(12,13)$.

\section{Objectives}

LSG with HHR has been recently proposed to manage a symptomatic HH in morbid obese patients (14). This paper meant to report our experience of twenty patients submitted to LSG with simultaneous crural repair in our department.

\section{Patients and Methods}

\subsection{Patients}

From July 2009 to November 2011, 20 patients with morbid obesity underwent LSG. Fourteen patients were female (70\%), mean BMI was $43.4 \pm 1.9 \mathrm{~kg} / \mathrm{m}^{2}$, hiatus hernia $(\mathrm{HH})$ was present in all patients, 18 of them were symptomatic and the remaining two were asymptomatic. The inclusion criteria were morbidly obese patients (BMI 39-56), non-sweet eaters, patients with no endocrinal cause for their obesity and also the patients who had failed in all restrictive diet measures to lose weight, patients with no previous upper GIT surgery, patients with hiatus hernia either the 18 symptomatic patients, or the two asymptomatic patients. The Exclusion criteria were, morbidly obese patients with no reflux symptoms or hiatus hernia on preoperative studies, sweet eaters, patients with psychological troubles and patients with previous upper GIT surgeries. LSG associated with hiatal hernia repair was done for all patients. All patients underwent a preoperative work-up including history and physical examination, routine laboratory investigations, ECG, chest radiography, pulmonary function tests, abdominal ultrasonography, and barium swallow, upper GIT endoscopy, 24 hours PH monitoring, nutritional, and psychiatric evaluation. Further exams and/or consultations were performed when indicated. The study design was a prospective non-comparative clinical study that received approval from the ethics committee in relevant hospitals. All the patients gave an informed written consent.

\subsection{Surgical Procedure}

Under a general anesthesia, the patient was placed in the split-leg position with the surgeon standing between the legs and the assistant on the left-hand side of the patient. A veress needle was used to create the pneumoperitoneum. Three 12-mm trocars were inserted in the upper abdomen (one on the right, two on the left side) and one 5 -mm trocar was inserted laterally in the left-upper quadrant. Retractor (Cook Biotech Inc., West Lafayette, IN) was inserted through the subxyphoid $10 \mathrm{~mm}$ trocar site to retract the liver (five to seven Trocars always used) (Figure 1). The hiatal hernia sac containing the proximal stomach was reduced. Distal esophagus and gastroesophageal junction were mobilized by using a laparoscopic Harmonic Scalpel (Ethicon Endo-Surgery Inc., Cincinnati, $\mathrm{OH}$ ) to get a $4-\mathrm{cm}$ tension-free intra-abdominal esophagus. Posterior crural repair was performed with three interrupted sutures of 2-0 Ethibond (Ethicon Inc., Somerville, NJ). To reinforce the repair, an onlay biologic mesh (Surgisis; Cook Biotech Inc.) in "U" configuration was fixed in place using hernia staplers. Sleeve gastrectomy was started by dividing the omentum off the greater curve at $6 \mathrm{~cm}$ from the pylorus all the way up to the gastroesophageal junction. Adhesions between the stomach and pancreas were 

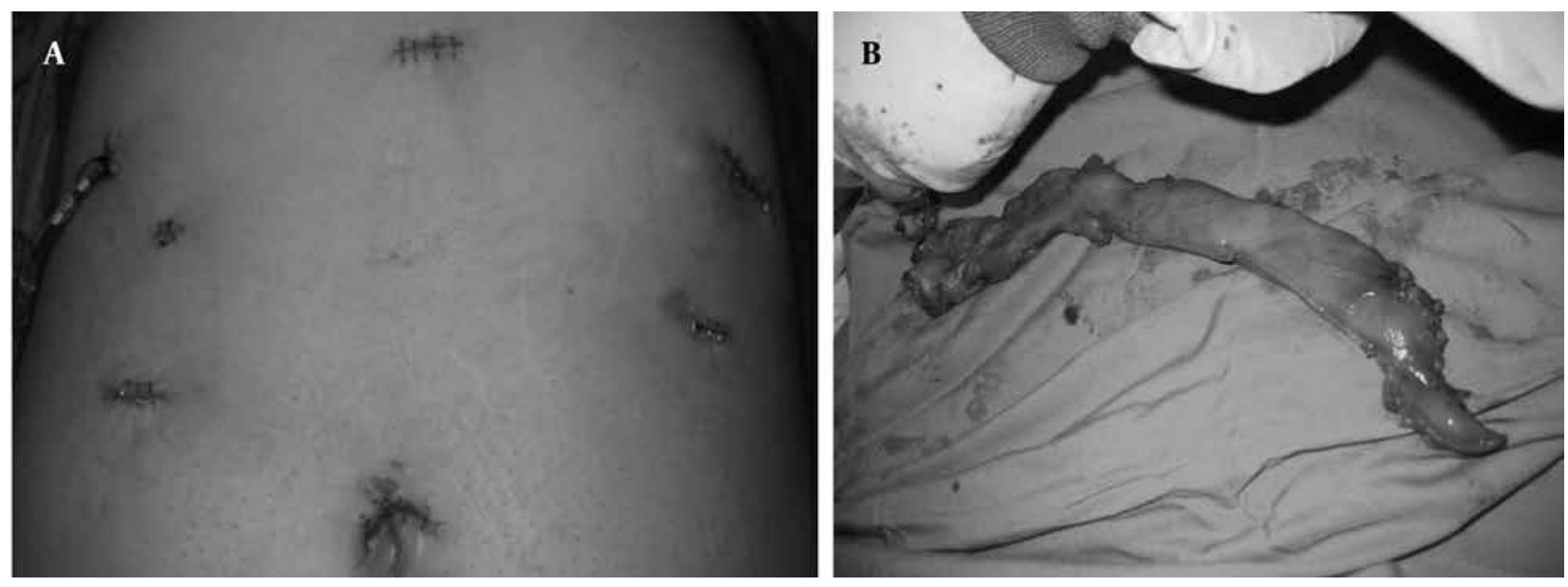

Figure 1. A) Port Sites; B) Sleeve Gastrectomy Specimen

released. A 4.8-mm (green) Endo-GIA stapler (Ethicon; Cincinnati, $\mathrm{OH}$ ) was fired $6 \mathrm{~cm}$ from the pylorus (preserving most of the antrum) toward the angle of His. A 36-F Maloney bougie was inserted along the lesser curve and the rest of the sleeve gastrectomy was completed, using a 3.8-mm (blue) Endo-GIA stapler. The green staple line was over sewn with 3-0 continuous vicryl sutures. The residual stomach was filled with methylene blue to check for the leak and to measure the capacity. Gastrectomy specimen was retrieved in an endobag through the leftupper quadrant-port wound. Intra-abdominal drain was inserted. There was no perioperative complication. On postoperative day 1 , a gastrograffin swallow showed no evidence of leak and the patient started a liquid diet. On postoperative day 2 , the patient was discharged from hospital with instructions to take a liquid diet for 2 weeks, followed by a pureed diet for 2 weeks (Figure 2). Three months after the procedure, a subjective reassessment of the symptoms was done. This study was prospective, non-comparative, and clinical, that evaluated the effects of crural repair on reflux symptoms commonly occurring in morbidly obese patients.

\begin{tabular}{ll}
\hline Table 1. Patient Demographics & \\
\hline & Value \\
\hline Gender & 14 \\
Female & 6 \\
Male & 8 \\
Smoker & $47(24-66)$ \\
Age, y, mean (rang) & $168(110-221)$ \\
Weight, kg, mean (rang) & $43.4(39-56)$ \\
Body mass index, kg/m², mean (rang) & $39 \pm 14(27-63)$ \\
Excess weight loss, \%, mean \pm SD (rang) & $28(24-36)$ \\
Follow-up, w, mean (rang) & $95(65-125)$ \\
Operative time, min, mean (rang) & 0 \\
Postoperative leak, No. & 0 \\
Mortality, No. &
\end{tabular}

\section{Results}

Twenty patients with a mean BMI of $43.4 \pm 1.9 \mathrm{~kg} / \mathrm{m}^{2}$ underwent LSG and HHR in our department from July 2009 to November 2011 (Table 1). 18 patients had a history of reflux and were taking antireflux medications before surgery, namely proton pump inhibitors (PPI). In these patients, $\mathrm{HH}$ was diagnosed during preoperative workup, and in two cases, it was $>5 \mathrm{~cm}$. The remaining two patients were asymptomatic, and $\mathrm{HH}$ was diagnosed intra-operatively (Table 2). All crural repair and sleeve gastrectomy were completed laparoscopically. In 18 cases, crural repair was performed by means of two or three interrupted non-absorbable stitches, while in the two cases with a $\mathrm{HH}>5 \mathrm{~cm}$, a U shaped polypropylene mesh was superimposed to aid crural closure. Mortality was nil and no pre- and post-operative complications occurred. The median operative time was $90 \mathrm{~min}$ (range 65-125). After a mean follow-up of seven months, median BMI was found to have fallen to $36.2 \pm 3.2 \mathrm{~kg} / \mathrm{m}^{2}$ after seven months. On a scale of 1-10 for severity, it was found that the heartburn improved from eight to three, chest pain from seven to three, and reflux from six to one. The patients lost an average $30.5 \%$ (45kg) of their excess body weight (7\% decrease in BMI) with improvement in gastro- esophageal reflux symptoms. 13 outof the 18 symptomatic patients report-

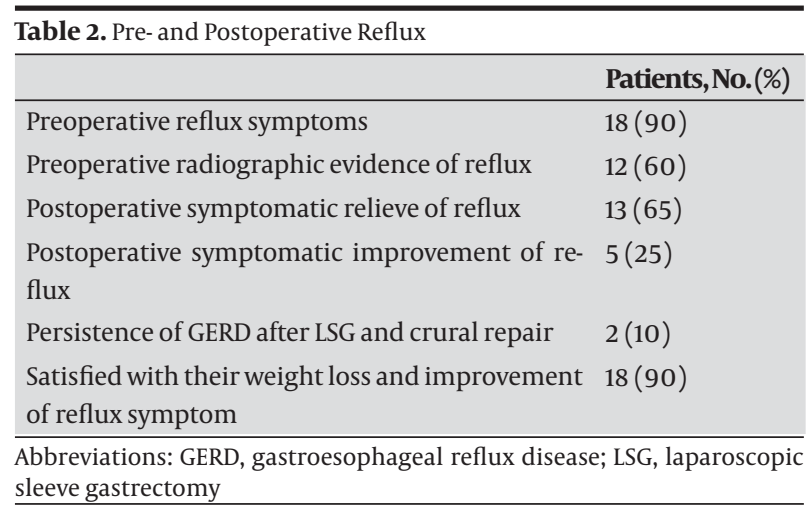



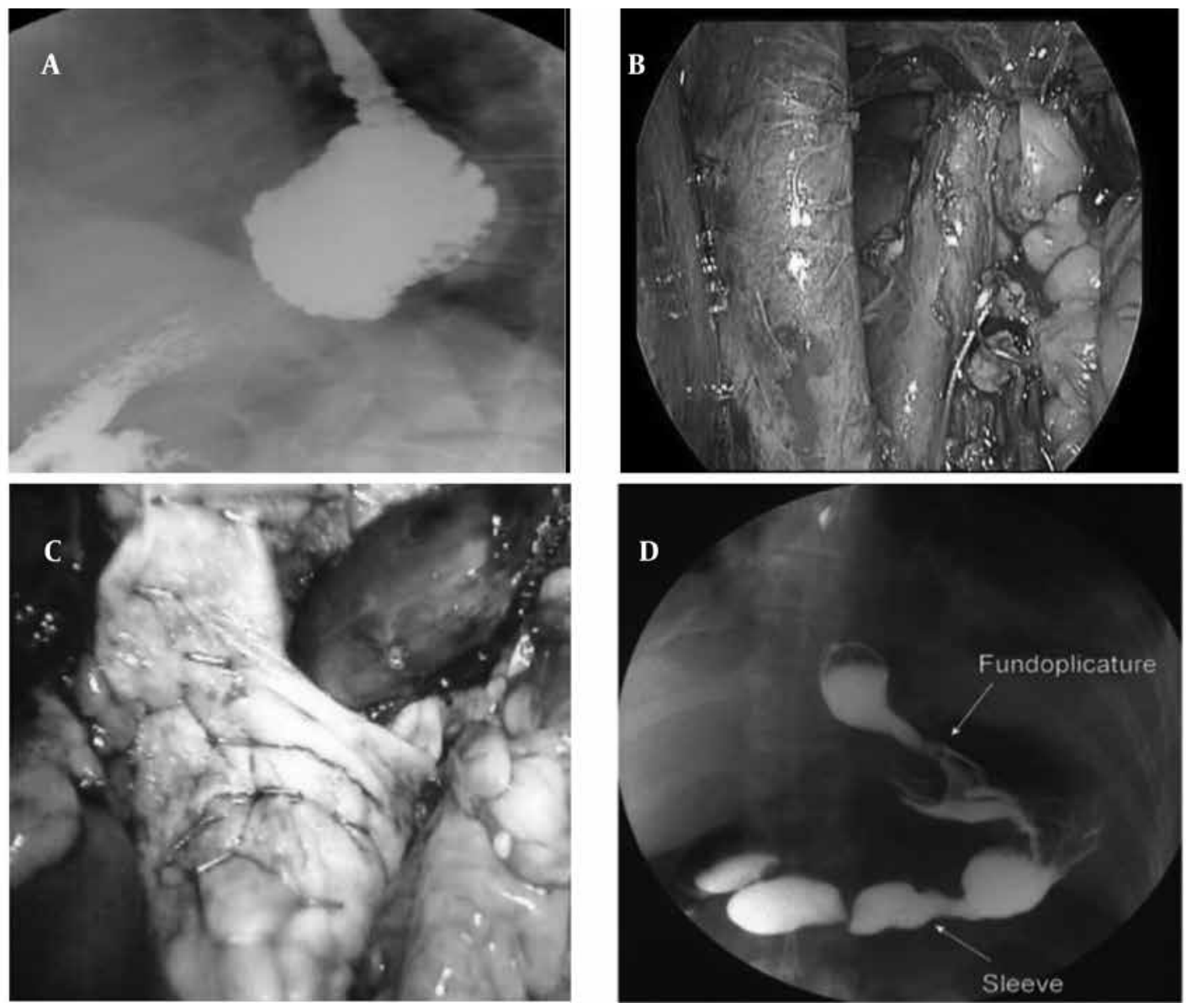

Figure 2. A) Barium Swallows Before Operation; B) laparoscopic sleeve gastrectomy (LSG)+ Crural Repair; C) Mesh Reinforcement After Crural Repair; D) Barium Study After Operation

ed resolution of GERD symptoms and stopped antireflux medications. Five patients reported an improvement of GERD and that a minimal dose of PPI ( $20 \mathrm{mg} /$ day $)$ well controlled the symptoms (Table 3). All patients underwent an upper gastrointestinal contrast (Gastrografin) study, one month after surgery. Upper gastrointestinal endoscopy (Figure 3) confirmed the evidence of GERD symptoms persistence and $\mathrm{HH}$ recurrence observed in two patients (10\%).

\section{Discussion}

GERD is one of the most common disorders of the upper gastrointestinal tract, affecting about $20 \%$ of the general population (15). Morbid obesity is found to be an independent risk factor for hiatus hernia and gastroesophageal reflux disease; about 50-70\% of morbid obese patients suffer from symptomatic reflux, and hiatus hernia is diagnosed in about $15 \%$ of patients with a BMI > 35 $\mathrm{kg} / \mathrm{m}^{2}(16)$. The physiopathological mechanisms of the

\begin{tabular}{lll}
\hline \multicolumn{2}{l}{ Table 3. Work up Gastroesophageal Reflux and Reflux Esophagitis Before and After Laparoscopic Sleeve Gastrectomy and Crural Repair } \\
\hline & \multicolumn{1}{l}{ Preoperative, No. $(\%)$} & Postoperative, No. (\%) \\
\hline Reflux symptoms $(\mathrm{n}=18)$ & $18(90)$ & \\
Endoscopy $(\mathrm{n}=18)$ & $10(50)$ & $0(0)$ \\
Dilated cardia without esophagitis & $6(30)$ & $0(0)$ \\
Dilated cardia with esophagitis & $18(90)$ & $2(10)$ \\
Hiatal Hernia & & \\
24h pH monitoring $(\mathrm{n}=18)$ & $18(90)$ & $2(10)$ \\
Abnormal acid reflux & & \\
Radiology ( $=18)$ & $18(90)$ & $7(35)$ \\
Presence of reflux & $16(80)$ & $2(10)$ \\
Dilated cardia & $18(90)$ & $2(10)$ \\
Hiatal hernia & & \\
\end{tabular}




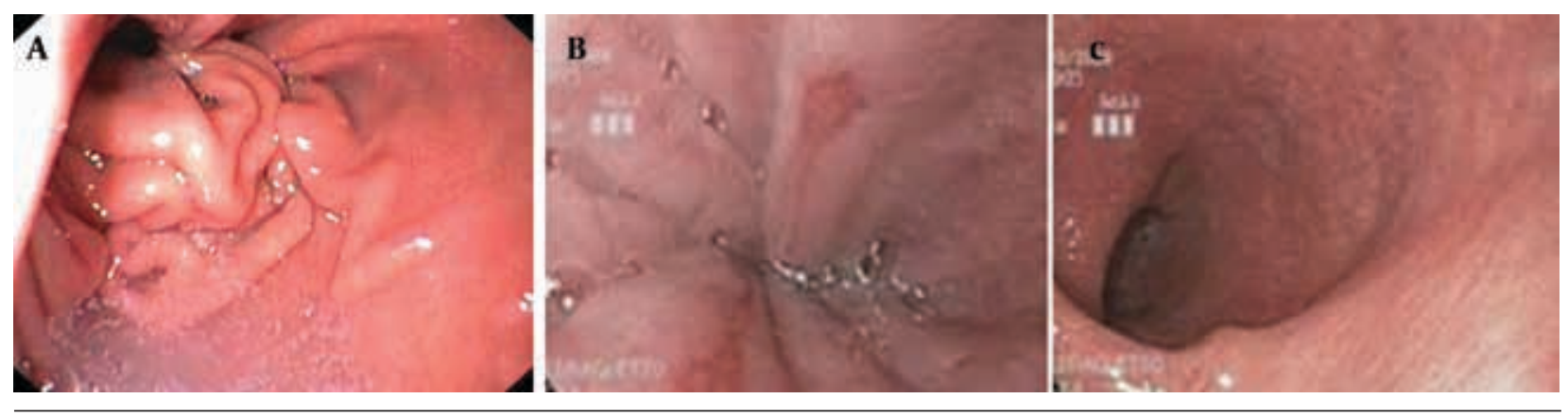

Figure 3. A) Hiatus Hernia; B) Grade A Esophagitis Stomach One Month After sleeve gastrectomy; C) Endoscopic View One Month After sleeve gastrectomy

obesity-induced GERD are not clearly found yet. The most likely hypothesis is that obesity causes a chronic increase of the intra-abdominal pressure, which in turn is inducing the reflux of the gastric content through an ineffective lower esophageal sphincter; also the presence of $\mathrm{HH}$ could further impair the antireflux mechanisms,which are worsening the GERD symptoms (17). Regardless of obese or non-obese patients, the surgical management of gastroesophageal reflux and/or $\mathrm{HH}$ aim to restore the cardioesophageal competence (18). High failure rates are reported following laparoscopic Nissen fundoplication in morbidly obese patients (BMI > 35), as a result, bariatric operations such as laparoscopic gastric banding (LGB) and laparoscopic Roux-en-Y gastric bypass(LRYGBP) have been considered as both antireflux and restrictive procedures because of their efficacy on weight loss and restoration of cardioesophageal competence (19). At the beginning, LGB seemed to be contraindicated in obese patients with $\mathrm{HH}$, because of the increased risk of band slippage or dysphagia, but afterward it was proved by several authors that not only crural repair in addition to gastric banding does not increase the risk of slippage or dysphagia , but it also significantly improves reflux symptoms, by providing an increase in lower esophageal sphincter pressure (20). LRYGBP has also been considered as an effective procedure to manage GERD and/or $\mathrm{HH}$, with several mechanisms of action (21). GERD improvement can be more likely related to weight loss, low acid production in the gastric pouch, and diversion of biliary contents from gastro-jejunal anastomosis. Additionally, gastric fixation by means of the mesenteric axis of the alimentary loop, reduces the risk of a new viscera herniation in the abdominal cavity (22-24). At present, LSG is considered to be a safe and effective bariatric procedure, similar in results with those of LRYGBP, superior to LGB in terms of weight loss, and low in rate of postoperative morbidity (25). The development of GERD symptoms in patients undergoing LSG indicates a quite common complication, although the incidence varies from $2.1 \%$ to $24.9 \%$ in large series of patients with a minimum follow-up of 12 months $(26,27)$. It may be related to the anatomic disruption of the angle of His ,and the alteration in the rate of gastric emptying (26). Symptoms of GERD are common especially in the first few months after LSG; nevertheless, they are generally responsive to PPI treatment, and seem to decrease over time (28). Moreover a $40-85 \%$ of patients who present clinical signs of GERD before surgery may improve by LSG (29). This could be explained by the postoperative weight loss, but it could also be related to the increase of the gastric compliance and emptying. Preservation of the antrum and the normal gastric emptying process through the pylorus, helps reduce gastric intraluminal pressure $(29,30)$. Restoring the stretched hiatus to normal by hiatoplasty and strengthening it with a mesh can restore the position and function of the lower esophageal sphincter and improve the GERD symptoms. $(26,27,31)$. At present, there are only two case reports concerning the use of LSG for morbid obesity treatment, complicated by $\mathrm{HH}$. In the first paper by Cuenca-Abente et al. LSG and crural repair were performed in a 60-yearold obese woman (BMI $46 \mathrm{~kg} / \mathrm{m} 2$ ), previously submitted to open paraesophageal hernia repair with Nissen fundoplication, because of the symptomatic recurrence of the hernia. According to the authors, LSG has been preferred to LRYGBP to prevent the risk of gastric volvulus in case of hiatal repair failure and to avoid anastomotic leakage, which may occur more frequently in patients with prior gastric surgery (32). The other paper, Bernante et al. reported the case of an LSG performed as rescue treatment in an obese patient with gastric banding for acute gastric necrosis due to a strangulated paraesophageal hernia (33). In this case, sleeve gastrectomy (SG) represented a good option to safely treat, simultaniously and in an urgent setting, both gastric necrosis and paraesophageal hernia, avoiding weight regain after band removal and potential complications of paraesophageal hernias, such as gastric volvulus (33). In the first case, the hiatal defect was large, and a posterior hiatoplasty was performed. In the other case, the authors did not perform hiatal repair, believing that scar tissue caused by the previous band could help to fix the gastroesophageal junction within the abdomen. Both patients did not experience postoperative complications, and after six and 18 months follow up, the weight loss was good, and there was no evidence of hernia recurrence $(33,34)$.

We first performed posterior hiatoplasty in addition 
to LSG, in July 2009, on an obese patient with symptomatic HH. Resolution of patient's GERD symptoms and interruption of PPI therapy encouraged us to perform hiatoplasty in the subsequent cases, when an $\mathrm{HH}$ had been diagnosed. As a result, at a mean follow-up of seven months, 13 of the 20 patients (65\%), submitted to LSG and crural repair, reported the resolution of the GERD symptoms, no need for antireflux medications, and no recurrence at postoperative barium swallow. In five patients, GERD symptoms were well controlled by a minimal dose of PPI. Similar to other reports, in our study, HH has been diagnosed preoperatively in 18 out of 20 cases, while in the other two cases; an asymptomatic HH has been diagnosed only during the bariatric procedure. The accurate dissection of the left pillar, necessary to perform LSG properly, diminishes the chances of missed diagnosis and helps in defining $\mathrm{HH}$ also in dubious cases. On the other hand, greater curvature skeletonization makes the approach to the hiatal crura simpler, allowing us to perform it from the left or right diaphragmatic pillar. Concerning the reinforcement of the hiatal repair with a shaped mesh, it was performed in two symptomatic cases with a hiatal defect $>5 \mathrm{~cm}$ (identified intraoperative) and in which pillars could not be approximated without tension. It has been proved in several large series (9)and in our experience that this technique significantly lowers the recurrence rate of $\mathrm{HH}$ in patients with a hiatal defect $>5 \mathrm{~cm}$.

Laparoscopic crural closure, in addition to LSG, can represent a valuable option for the synchronous management of morbid obesity and $\mathrm{HH}$, and can result good outcomes in terms of weight loss and GERD symptoms control. The prosthetic reinforcement of the hiatal closure should be performed in selected cases when an increased risk of $\mathrm{HH}$ recurrence exists. Further series with a larger number of patients and long-term follow- up are needed to evaluate the efficacy of this procedure, and also the feasibility and safety of prosthetic hiatal closure.

\section{Acknowledgements}

None declared.

\section{Authors' Contribution}

None declared.

\section{Financial Disclosure}

None declared.

\section{Funding/Support}

None declared.

\section{References}

1. El-Serag H. The association between obesity and GERD: a review of the epidemiological evidence. Dig Dis Sci. 2008;53(9):2307-12.

2. Clements RH, Gonzalez QH, Foster A, Richards WO, McDowell J,
Bondora A, et al. Gastrointestinal symptoms are more intense in morbidly obese patients and are improved with laparoscopic Roux-en-Y gastric bypass. Obes Surg. 2003;13(4):610-4.

3. Hampel H, Abraham NS, El-Serag HB. Meta-analysis: obesity and the risk for gastroesophageal reflux disease and its complications. Ann Intern Med. 2005;143(3):199-211.

4. Braghetto I, Korn O, Valladares H, Gutiérrez L, Csendes A, Debandi A, et al. Laparoscopic sleeve gastrectomy: surgical technique, indications and clinical results. Obes Surg. 2007;17(11):1442-50.

5. Pandolfino JE. The relationship between obesity and GERD: "big or overblown". Am J Gastroenterol. 2008;103(6):1355-7.

6. Wilson LJ, Ma W, Hirschowitz BI. Association of obesity with hiatal hernia and esophagitis. Am J Gastroenterol. 1999;94(10):28404.

7. Morgenthal CB, Lin E, Shane MD, Hunter JG, Smith CD. Who will fail laparoscopic Nissen fundoplication? Preoperative prediction of long-term outcomes. Surg Endosc. 2007;21(11):1978-84.

8. Gulkarov I, Wetterau M, Ren CJ, Fielding GA. Hiatal hernia repair at the initial laparoscopic adjustable gastric band operation reduces the need for reoperation. Surg Endosc. 2008;22(4):1035-41.

9. Nocca D, Krawczykowsky D, Bomans B, Noel P, Picot MC, Blanc $\mathrm{PM}$, et al. A prospective multicenter study of 163 sleeve gastrectomies: results at 1 and 2 years. Obes Surg. 2008;18(5):560-5.

10. Parikh M, Gagner M. Laparoscopic hiatal hernia repair and repeat sleeve gastrectomy for gastroesophageal reflux disease after duodenal switch. Surg Obes Relat Dis. 2008;4(1):73-5

11. Anand G, Katz PO. Gastroesophageal reflux disease and obesity. Rev Gastroenterol Disord. 2008;8(4):233-9.

12. Hagen J, Deitel M, Khanna RK, Ilves R. Gastroesophageal reflux in the massively obese. Int Surg. 1987;72(1):1-3.

13. Lundell L, Ruth M, Sandberg N, Bove-Nielsen M. Does massive obesity promote abnormal gastroesophageal reflux? Dig Dis Sci. 1995;40(8):1632-5.

14. Frigg A, Peterli R, Zynamon A, Lang C, Tondelli P. Radiologic and endoscopic evaluation for laparoscopic adjustable gastric banding: preoperative and follow-up. Obes Surg. 2001;11(5):594-9.

15. Ovrebo KK, Hatlebakk JG, Viste A, Bassoe HH, Svanes K. Gastroesophageal reflux in morbidly obese patients treated with gastric banding or vertical banded gastroplasty. Ann Surg. 1998;228(1):51-8.

16. Granderath FA, Carlson MA, Champion JK, Szold A, Basso N, Pointner $\mathrm{R}$, et al. Prosthetic closure of the esophageal hiatus in large hiatal hernia repair and laparoscopic antireflux surgery. Surg Endosc. 2006;20(3):367-79.

17. Granderath FA, Kamolz T, Schweiger UM, Pointner R. Quality of life, surgical outcome, and patient satisfaction three years after laparoscopic Nissen fundoplication. World J Surg. 2002;26(10):1234-8

18. Carlson MA, Frantzides CT. Complications and results of primary minimally invasive antireflux procedures: a review of 10,735 reported cases. J Am Coll Surg. 2001;193(4):428-39.

19. Basso N, De Leo A, Genco A, Rosato P, Rea S, Spaziani E, et al. 360 degrees laparoscopic fundoplication with tension-free hiatoplasty in the treatment of symptomatic gastroesophageal reflux disease. Surg Endosc. 2000;14(2):164-9.

20. Soricelli E, Basso N, Genco A, Cipriano M. Long-term results of hiatal hernia mesh repair and antireflux laparoscopic surgery. Surg Endosc. 2009;23(11):2499-504.

21. Frantzides CT, Madan AK, Carlson MA, Stavropoulos GP. A prospective, randomized trial of laparoscopic polytetrafluoroethylene (PTFE) patch repair vs simple cruroplasty for large hiatal hernia. Arch Surg. 2002;137(6):649-52.

22. Dolan K, Finch R, Fielding G. Laparoscopic gastric banding and crural repair in the obese patient with a hiatal hernia. Obes Surg. 2003;13(5):772-5.

23. Granderath FA, Schweiger UM, Kamolz T, Asche KU, Pointner R. Laparoscopic Nissen fundoplication with prosthetic hiata closure reduces postoperative intrathoracic wrap herniation: preliminary results of a prospective randomized functional and clinical study. Arch Surg. 2005;140(1):40-8.

24. Landen S. Simultaneous paraesophageal hernia repair and gas- 
tric banding. Obes Surg. 2005;15(3):435-8.

25. Perry Y, Courcoulas AP, Fernando HC, Buenaventura PO, McCaughan JS, Luketich JD. Laparoscopic Roux-en-Y gastric bypass for recalcitrant gastroesophageal reflux disease in morbidly obese patients. JSLS. 2004;8(1):19-23.

26. Frezza EE, Ikramuddin S, Gourash W, Rakitt T, Kingston A, Luketich J, et al. Symptomatic improvement in gastroesophageal reflux disease (GERD) following laparoscopic Roux-en-Y gastric bypass. Surg Endosc. 2002;16(7):1027-31.

27. Salvador-Sanchis JL, Martinez-Ramos D, Herfarth A, RivadullaSerrano I, Ibanez-Belenguer M, Hoashi JS. Treatment of morbid obesity and hiatal paraesophageal hernia by laparoscopic Rouxen-Y gastric bypass. Obes Surg. 2010;20(6):801-3.

28. Patterson EJ, Davis DG, Khajanchee Y, Swanstrom LL. Comparison of objective outcomes following laparoscopic Nissen fundoplication versus laparoscopic gastric bypass in the morbidly obese with heartburn. Surg Endosc. 2003;17(10):1561-5.

29. Zainabadi K, Courcoulas AP, Awais O, Raftopoulos I. Laparoscopic revision of Nissen fundoplication to Roux-en-Y gastric bypass in morbidly obese patients. Surg Endosc. 2008;22(12):2737-40.

30. Mercer CD, Wren SF, DaCosta LR, Beck IT. Lower esophageal sphincter pressure and gastroesophageal pressure gradients in excessively obese patients. J Med.1987;18(3-4):135-46.

31. Greenstein RJ, Nissan A, Jaffin B. Esophageal anatomy and function in laparoscopic gastric restrictive bariatric surgery: implications for patient selection. Obes Surg. 1998;8(2):199-206.

32. Cuenca-Abente F, Parra JD, Oelschlager BK. Laparoscopic sleeve gastrectomy: an alternative for recurrent paraesophageal hernias in obese patients. JSLS. 2006;10(1):86-9.

33. Bernante P, Breda C, Zangrandi F, Pomerri F, Pelizzo MR, Foletto $\mathrm{M}$. Emergency sleeve gastrectomy as rescue treatment for acute gastric necrosis due to type II paraesophageal hernia in an obese woman with gastric banding. Obes Surg. 2008;18(6):737-41.

34. Casella G, Soricelli E, Rizzello M, Trentino P, Fiocca F, Fantini A, et al. Nonsurgical treatment of staple line leaks after laparoscopic sleeve gastrectomy. Obes Surg. 2009;19(7):821-6. 